\title{
Supporting student transitions to placement and work: developing a new self-identity
}

\author{
Gemma Webster*, Sally Smith \& Colin Smith \\ Edinburgh Napier University \\ *Corresponding Author: G.Webster@napier.ac.uk
}

Keywords: student identity, placement, professional identity

\begin{abstract}
Moves towards the marketisation of higher education together with concerns over the challenges of graduate employment have led to an increased prioritisation of students undertaking relevant work experience while they study. Recognising a strong student demand for placements, universities are establishing employability initiatives including those designed to increase the availability of quality paid placements for students. To complement this activity, industry, sectorspecific, regional placement projects such as e-Placement Scotland, take an employer-led approach to maximise opportunities for students across a number of universities. In spite of these initiatives, not every student will successfully obtain a placement, and so ePlacement Scotland aims to 'add value' for students in various other ways. Interventions such as industry tech talks and speed networking sessions have been deployed to develop awareness of the employment landscape and encourage students to start thinking about their self-identification, easing their transition into the workplace. Adopting the lens of identity theory, this study explores student and professional identity in order to recognise the transition from student to graduate, and to consider the role of placement and other value-adding activities in that transition. The study found that, while the incidence of students self-identifying as professionals increases in later years of their courses, placement preparation interventions did not themselves have an observable effect.
\end{abstract}

These findings challenge the project assumption that placement preparation activities can offer students valuable insights that can help them identify with their profession.

\section{Context}

Universities are no longer free to dictate curricula with scant regard for graduate outcomes. Moves towards marketisation in higher education have encouraged universities to place a higher priority on employability within both curricula design and centralised careers services. The value of relevant work experience to students is well established (e.g. Brooks, 2012). However universities are not able to control the supply of industry placements, with the result that some students are unable, or unwilling, to access these opportunities. Responding to some of these challenges, projects such as e-Placement Scotland have set out to increase the availability of paid placement opportunities. In the case of e-Placement Scotland the placements are specifically for students in computing programmes. Recognising, however, that not every student will choose to undertake a placement or successfully apply, one of the aims of the project is to add value to students' work-related experience whether or not they secure a placement. Value-adding events, such as industry 'tech talks' and speed networking sessions, can heighten industry awareness and prepare students for placement and graduate jobs (Pierrakos, Beam, Constantz, Johri \& Anderson, 2009). A 
greater awareness of the impact of these, and other experiences, on students' emerging sense of selves as professionals could help universities identify meaningful alternatives to a work placement. This study was designed to gain insights, through the lens of role theory, into the impact of placement and value-adding events that could mitigate against a lack of relevant placement experience.

\section{Theory}

Role theory allows for an examination of our self-identity through the roles we hold, for example as student or professional (Serpe \& Stryker, 2011). Role theory holds that behaviour is to some extent predictable based on the roles that individuals hold., Studies focusing on role enactment and role performance, such as the role of 'student', with subsequent expectations of typical behaviour (Holden et al. 2015, Langendyk et al. 2015). This holds true for both student and professional identities, with the norms and behaviours being quite different for each identity. Professional identity has been described as a self-concept which an individual constructs from their skills, experience, attributes and values in a professional role (Ibarra, 1999; Beijaard et al., 2009). The term pre-professional identity has been used to encompass the skills and capabilities of students together with 'conduct, culture and ideology of a student's intended profession' (Jackson, 2016). Pre-professional identity been observed emerging through such initiation events as students being asked to consider the values and behaviours of a profession (Loui, 2005), or being asked to undertake approximations of workplace practice through role-playing (Ronfeldt \& Grossman, 2008). Students are deemed to begin feeling like a professional, as they start to prepare for a professional role (Crossley \& Vivekananda-Schmidt, 2009).

Previous research on the influence of workbased learning has found that work-based and work-integrated learning are ideal arenas for students to develop their professionalism and professional identities (Trede, 2012; Smith et al., 2014). Participating in activities that relate to the profession has been found to help students identify as professionals (Lave \& Wenger, 1991). However, delays in developing a professional self-identity can present a barrier to the successful transition from student to professional (Schwertner et al., 1987). Furthermore, self-identity is affected by social, demographic and personality factors in addition to exposure to professional practices (Chamberlain et al., 2005).

Research into employer perspectives on requirements from graduates emphasises skills and knowledge, together with teamworking capability, communication skills and demonstrating a positive attitude to work (Griesel and Parker 2009, Hernández-March, Martín del Peso \& Leguey 2009). In a changing employment landscape, the phenomenon of relatively high unemployment rates among computing students in the UK has attracted policy and media attention (for example Gilbey 2016). Some attempts have been made to uncover the factors contributing to this phenomenon (most recently, Shadbolt 2016). Various reports point to a gap between employer expectations and graduate profiles (for example, House of Commons Science and Technology Committee, 2016; Doherty and Fernandez, 2014). Indeed research into employer expectations reveals a complex landscape of different requirements based on sector, company size and less predictable factors such as 'cultural fit' (Smith and Smith 2016). In recent years, careers have become less predictable, with fewer examples or expectations of stable, lifelong career trajectories, instead graduates experience increasingly frequent transitions (Savickas 2005) which points to employability now having to encompass adaptability and flexibility as core elements (Yorke \& Knight 2007, Tomlinson 2007). With fewer graduate vacancies than graduates (Green and Zhu 2010, Abel, Deitz, and Su 2014, Docherty and Fernandez 2014), some sectors are turning to evidence beyond degree classification, such as extra-curricular activity (Jing, Patel \& Chalk 2011, Oliver 2013) which, for computing, encompasses personal projects, competitions, social media presence as well as more traditional activity such as placement. Gaining graduate employment in this context is a challenge for students who are increasingly considering their employability prospects and anticipated return on investment (Chan, Brown \& Ludlow 2014). University-level policies, practices and evaluation models are now 
commonplace (for example, Kinash et al. 2014, Oliver 2013, Smith 2016, Dacre, Pool \& Sewell 2007). Reconsideration of the nature of the impact of placement, to encompass not just placement itself but also activities designed to raise awareness of placement within an industry sector, on students' self-identification is the focus of this study.

In particular, this study was designed to explore students' self-identification as professionals, and to identify factors that might mitigate against a lack of relevant work experience.

\section{Method}

To examine the effect exposure to professional practices/activities has on students self-identity a questionnaire was developed that could be repeatedly administered throughout a student's time on their university course, to gauge the effectiveness of activities in helping students form their professional selves. The findings from these surveys can be used to consider the impact of activities in order to determine which should be integrated into dayto-day teaching.

A review of other disciplines that have strong links between the university course and professional identity was undertaken to explore if any suitable techniques or processes could be adapted from those domains to computer science. It was found that medicine, social care and dentistry have some of the closest links between student and professional identity.

The development and evaluation of a Professional Self Identity Questionnaire (PSIQ) to measure evolving professional selfidentity in health and social care students was found to be a suitable tool to be adapted to computer science students (Crossley \& Vivekananda-Schmidt, 2009). This tool was selected as it had been validated, was simple and quick to administer and could be easily and usefully contextualised to the computer science domain. The PSIQ survey has been found to provide a valid measure of the emerging self-identification of students as professionals (Crossley \& Vivekananda-

\footnotetext{
1 http://www.bcs.org/category/5844

2 https://www.sfia-online.org/en

3 http://www.engc.org.uk/UKSPEC
}

Schmidt, 2009). A further reason for the selection of this tool was that it does not try to define professionalism closely - important since recognition of a close definition might vary across different respondent groups. Instead the definition is left open to allow respondents to apply their own perceptions of professionalism. The instrument reflects different domains of activity common to the discipline, and relevant quality and benchmarking documentation for computer science disciplines was drawn upon to develop the questionnaire. These included:

- British Computer Society - course accreditation $^{1}$

- SFIA 5 framework ${ }^{2}$

- Chartered engineering standard for professional competence ${ }^{3}$

- Chartered IT professional ${ }^{4}$

- ACM curriculum guidelines for undergraduate courses ${ }^{5}$

These documents were analysed to define four over-arching themes that all addressed skills or qualities which students should have when graduating. The four themes were:

- Knowledge and understanding (questions 1, 2)

- Application of knowledge and skills (questions 3, 4)

- Transferable I interpersonal skills (questions 5, 6)

- Professional skills (questions 7, 8, 9)

The researcher mapped these themes onto the PSIQ and created nine questions. The content of the questions was developed by re-visiting the source documents to ensure consistent phrasing with the language used by the professional bodies. The skills and language used were deliberately generic to cover the widest possible strands of computer science degree programs. The questions are detailed in the Appendix.

Open statements were used, such as the example of question one: "when reflecting on my knowledge and understanding of essential

\footnotetext{
${ }^{4}$ http://www.bcs.org/category/10972

${ }^{5}$ http://www.acm.org/education/curricularecommendations
} 
concepts relating to my computing discipline I feel like a.......". Participants were asked to score their response to these on a 6-point Likert scale with options ranging from 'novice' to 'professional'.

Participants were also asked which placement preparation events they had attended. These ranged from 'visiting the careers service' to 'completing a paid placement'. As demographics and differential experiences also contribute to professional identity, relevant demographic data was recorded in the questionnaire. The questionnaire was deployed in three settings $(n=74)$ :

- 4th year students, on the submission of their capstone final projects

- 3rd year students in-class who had decided not to undertake a one year placement available as an option on their course

- 2nd year students about to begin a one year placement

The students varied in their year of study but were selected as they all had access to the same services, activities or events that could impact upon the construction of a professional identity. All 4th year students were recruited to participate during their project demonstrations. The 3rd year students were recruited to participate at the end of a lecture, and 2nd year students were invited to participate via the Work Based Learning module that awards credit for their one year placement. Edinburgh Napier University ethics procedures were followed in the development of the questionnaire and its application. The data were analysed in SPSS.

\section{Study Findings}

The gender and age of the respondents is typical of the balance in the computing discipline across the university. Table 1 includes information about the gender breakdown and the range of ages. The data was analysed to consider professional identity related to year of study, gender, age, attendance at placement preparation or careers events and previous placement experience.

\begin{tabular}{|c|c|c|c|c|}
\hline & $\mathbf{2}^{\text {nd }}$ Year & $\mathbf{3}^{\text {rd }}$ Year & $\mathbf{4}^{\text {th }}$ Year & All Students \\
\hline $\mathbf{N}$ & $19(24.4 \%)$ & $21(26.9 \%)$ & $34(43.6 \%)$ & 74 \\
\hline Male & $15(79 \%)$ & $17(81 \%)$ & $31(91.2 \%)$ & $63(85.1 \%)$ \\
\hline Age: $\mathbf{1 7 - 2 2}$ & 15 & 10 & 20 & 45 \\
\hline $\mathbf{2 3 - 2 8}$ & 0 & 5 & 10 & 15 \\
\hline $\mathbf{2 9 - 3 4}$ & 3 & 4 & 3 & 10 \\
\hline $\mathbf{3 5 - 4 0}$ & 0 & 1 & 0 & 1 \\
\hline $\mathbf{4 0 - 4 9}$ & 1 & 1 & 1 & 3 \\
\hline
\end{tabular}

Table 1 Summary of participant characteristics

Responses were significant for year of study, with higher scores returned by later years of study for questions 1-4 and 9. Question 1 related to essential facts, question 2 ability to analyse, questions 3 and 4 application of knowledge, finally question 9 related to understanding best practice and standards. The questions relating to teamworking, communication, learning new skills and ethics were not statistically significant for student respondents throughout different years of the course.

There was no statistically significant difference in professional identity score between different genders or for different age ranges for all questions. Nor was there a significant result on any questions for students who had attended events or activities compared with those who had attended no events or activities.

A significant difference was found between students who had completed a placement and those who had not for questions in each category (in particular 1, 3, 4, 6 and 9). Question 6 related to communication skills. Self-reported levels of professional competence for knowledge, reflection, problem solving, communicating and evaluation were all significantly higher for placement students 
over those who had not completed a placement. Although students with a placement experience are generally further on in their course, a difference in self-reported communication skills was observed between placed and non-placed students in the same cohort.

\section{Discussion}

The study showed that students in later years of their course increasingly identified as skilled computing professionals. Overall, selfidentification for placement and non-placement students was similar; Although students who completed a placement were more likely to claim communication skills, these skills are of value to placement employers and could have been a factor in securing a placement. While graduates have reported more developed communication skills associated with placement (Wilton, 2012), previous studies have pointed to variable placement experiences affecting the development of generic skills (Crebert, Bates, Bell, Patrick \& Cragnolini, 2004). A follow up pre- and postplacement study could be designed to reveal more about whether confidence in communication skills developed as a result of a placement experience.

Although the intention of the value-adding events was to benefit all students, not just those who secured a placement, the preplacement preparation events had no impact on the students' sense of self as a professional. McKinnon \& McCrae (2012) found that students had less confidence in their skills and abilities on completion of a work-related module with speculation that this was due to greater awareness of the challenges that lay ahead. Evidence elsewhere points to the importance of embedding meaningful employability activity in a discipline specific way (Oliver, 2013).

One further concern in this study was that students in later years did not change their view of their own ability to adapt (question 7). This is a concern for curriculum developers: for example, the report Digital Skills for the Economy (2016) identified the need for universities to ensure graduates are adaptable in the face of new technology. A closer examination of this question could determine if this was related to students not recognising their skills through a process of personal reflection, or whether it reflected reality.

In conclusion, to meet student demand for graduate employment, the challenge for universities should not be understated. One approach would be to create a secure pipeline of placements and design evidence-based meaningful alternatives that facilitate selfidentification as skilled graduates - easier said than done.

\section{References}

Brooks, R. (2012). Evaluating the impact of sandwich placements on employability. In Employability, enterprise and citizenship in higher education conference (Vol. 27).

Chamberlain, T.C., Catano, V.M. \& Cunningham, D.P. (2005). Personality as a predictor of professional behavior in dental school: comparisons with dental practitioners. Journal of Dental Education, 69(11), pp.1222-1237.

Crebert, G., Bates, M., Bell, B., Patrick, C.J. \& Cragnolini, V. (2004). Developing generic skills at university, during work placement and in employment: graduates' perceptions. Higher Education Research \& Development, 23(2), pp.147-165.

Crossley, J. \& Vivekananda-Schmidt, P. (2009). The development and evaluation of a Professional Self Identity Questionnaire to measure evolving professional self-identity in health and social care students. Medical teacher, 31(12), pp.e603-e607. DOI: 10.3109/01421590903193547

Department for Culture, Media \& Sport, Department for Business, Innovation \& Skills and Ed Vaizey MP, (2016). Digital Skills for the UK Economy. [online] Available at: https://www.gov.uk/government/publications/d igital-skills-for-the-uk-economy [Accessed 27 Sep. 2016].

Griesel, H. \& Parker, B. (2009). Graduate attributes: A baseline study on South African graduates from the perspective of employers. Pretoria: Higher Education South Africa. 
Hernández-March, J., Martín del Peso, M. \& Leguey, S. (2009). Graduates' skills and higher education: The employers' perspective. Tertiary Education and Management, 15(1), pp.1-16.

Holden, M.D., Buck, E., Luk, J., Ambriz, F., Boisaubin, E.V., Clark, M.A., Mihalic, A.P., Sadler, J.Z., Sapire, K.J., Spike, J.P. \& Vince, A. (2015). Professional identity formation: Creating a longitudinal framework through TIME (transformation in medical education). Academic Medicine, 90(6), pp.761-767.

Langendyk, V., Hegazi, I., Cowin, L., Johnson, M. \& Wilson, I. (2015). Imagining alternative professional identities: Reconfiguring professional boundaries between nursing students and medical students. Academic Medicine, 90(6), pp.732-737.

Lave, J. \& Wenger, E. (1991). Situated learning: Legitimate peripheral participation. Cambridge university press.

Loui, M.C. (2005). Ethics and the development of professional identities of engineering students. Journal of Engineering Education, 94(4), pp.383-390.

McKinnon, S. \& McCrae, J. (2012). Closing the gap: preparing computing students for employment through embedding work-related learning in the taught curriculum. Industry and Higher Education,26(4), pp.315-320.
Pierrakos, O., Beam, T.K., Constantz, J., Johri, A. \& Anderson, R. (2009). On the development of a professional identity: Engineering persisters vs engineering switchers. In 2009 39th IEEE Frontiers in Education Conference (pp. 1-6). IEEE.

Ronfeldt, M. \& Grossman, P. (2008). Becoming a professional: Experimenting with possible selves in professional preparation. Teacher Education Quarterly, 35(3), pp.41-60.

Schwertner, R.M., Pinkston, D., O'Sullivan, P. \& Denton, B. (1987). Transition from student to physical therapist. Physical therapy, 67(5), pp.695-701.

Smith, S., Sobolewska, E. \& Smith, I. (2014). From employability attributes to professional identity: students transitioning to the workplace. In 2014 IEEE Frontiers in Education Conference (FIE) Proceedings (pp. 1-8). IEEE.

Trede, F. (2012). Role of work-integrated learning in developing professionalism and professional identity. Asia-Pacific Journal of Cooperative Education, 13(3), pp.159-167.

Wilton, N. (2012). The impact of work placements on skills development and career outcomes for business and management graduates. Studies in Higher Education, 37(5), pp.603-620.,

DOI: $10.1080 / 03075079.2010 .532548$ 


\section{Appendix: Professional identity questions}

\begin{tabular}{|c|c|}
\hline Question Theme & Question \\
\hline $\begin{array}{l}\text { Knowledge and } \\
\text { understanding }\end{array}$ & $\begin{array}{l}\text { 1) When reflecting on my knowledge and understanding of essential facts, } \\
\text { concepts, principles and theories relating to my computing discipline I } \\
\text { feel like } a . . . . .\end{array}$ \\
\hline $\begin{array}{l}\text { Knowledge and } \\
\text { understanding }\end{array}$ & $\begin{array}{l}\text { 2) When reflecting on my ability to analyse a problem and identify and } \\
\text { define the requirements appropriate to its solution I feel like a...... }\end{array}$ \\
\hline $\begin{array}{l}\text { Application of } \\
\text { knowledge and skills }\end{array}$ & $\begin{array}{l}\text { 3) When reflecting on my ability to analyse the extent to which a solution } \\
\text { meets the criteria defined for its current use and future development I } \\
\text { feel like a...... }\end{array}$ \\
\hline $\begin{array}{l}\text { Application of } \\
\text { knowledge and skills }\end{array}$ & $\begin{array}{l}\text { 4) When I am using techniques, skills and tools to produce a solution to } \\
\text { meet a desired need I feel like a...... }\end{array}$ \\
\hline $\begin{array}{l}\text { Transferable / } \\
\text { interpersonal skills }\end{array}$ & $\begin{array}{l}\text { 5) When I am working as a member of a team with a range of different } \\
\text { roles within the team I feel like a...... }\end{array}$ \\
\hline $\begin{array}{l}\text { Transferable / } \\
\text { interpersonal skills }\end{array}$ & 6) When I am communicating with a range of audiences I feel like a...... \\
\hline Professional skills & 7) When learning a new skill I feel like a...... \\
\hline Professional skills & $\begin{array}{l}\text { 8) When I am considering professional, ethical, legal, security and social } \\
\text { issues and responsibilities I feel like a...... }\end{array}$ \\
\hline Professional skills & $\begin{array}{l}\text { 9) When evaluating my understanding of best practices and standards for } \\
\text { their application I feel like a...... }\end{array}$ \\
\hline
\end{tabular}

